\section{NANOTECHNOLOGY}

\section{DNA tiles yield} bigger arrays

DNA 'origami' describes the practice of using specially designed DNA molecules to guide the assembly of nanostructures into a variety of shapes. Now researchers have used DNA origami 'tiles' to form two-dimensional crystals with edges reaching 2-3 micrometres in length. This should allow larger and more complex structures to be created, say Nadrian Seeman and his colleagues at New York University.

The authors used crossshaped tiles - made from the DNA strands of the M13 virus - with uneven, or 'sticky' ends. Because the axes of the DNA helical strands were perpendicular, the tiles self-assembled in two dimensions to form arrays. This overcomes problems previously encountered with tiles that assembled mainly in one dimension, the authors say. Angew. Chem. Int. Edn doi:10.1002/anie.201005911 (2010)

\section{CELL BIOLOGY}

\section{Communication} key to cancer virus

A virus linked to many human cancers may promote the growth of uninfected neighbouring cells by mediating the transfer of key signalling and gene-regulatory molecules from infected cancer cells. These molecules are packaged in tiny sacs called exosomes, which are taken up by the nearby cells.

Nancy Raab-Traub and her team at the University of North Carolina at Chapel Hill isolated exosomes from cancer cells that had been infected with Epstein-Barr virus. They found that these contained high levels of LMP1, a protein encoded by the virus that enhances cell growth and is found in many cancers. After incubating normal cells with the exosomes, the authors found
LMP1 and activated growthsignalling pathways in the cells. The cells also contained viral microRNAs, which regulate gene expression, suggesting that the virus uses exosomes to manipulate its environment.

Proc. Natl Acad. Sci. USA

doi:10.1073/pnas.1014194107 (2010)

\section{GENETICS}

\section{Metabolic variation's roots}

Metabolism is under the control of a combination of heritable and environmental factors. Teasing out how these factors interact could help to explain why metabolism differs between individuals.

Daniel Kliebenstein at the University of California, Davis, and his colleagues looked for associations between more than 200,000 single-nucleotide variants across the genome and levels of 327 metabolites in 96 strains of Arabidopsis thaliana. They found that only $23-30 \%$ of the variation in cellular metabolite levels was associated with specific sites in the genome. The team also noted that high genetic variation was not associated with high metabolic variation.

The results suggest that many small gene effects control metabolism, and point to the need to examine metabolism under a range of environmental conditions to fully dissect its genetics.

PLoS Genet. 6, e1001198 (2010)

$$
\text { NUCLEAR PHYSICS }
$$

\section{Isotopes map uncharted realm}

The production of six new heavy isotopes promises to shed light on the shell model for nuclear structure of the periodic table's heavier elements.

The new nuclei - which fit into the periodic table between rutherfordium (element 104) and the as-yet-unnamed element 114 - were created in a single radioactive decay

COMMUNITY CHOICE

The most viewed papers in science

\title{
Brain connections have rhythm
}

\section{HIGHLY READ \\ on www.cell.com in October}

The number of neuron-to-neuron connections, or synapses, that an animal has is thought to vary from one time of day to another. A team of scientists at Stanford

University in California set out to watch the process in live zebrafish larvae, using time-lapse fluorescence microscopy.

Lior Appelbaum, currently at Bar-Ilan University in Ramat Gan, Israel, and his colleagues followed the creation and disappearance of synapses over a 24 -hour period. They focused on a particular class of neuron in two brain areas known to be involved in regulating sleeping and waking: the pineal gland and the hindbrain.

The authors showed that the number of synapses fluctuated rhythmically between day and night. They also found that a protein, Nptx2, for which levels in the brain also vary rhythmically during the 24-hour period, is involved in regulating the rhythmicity of synapse number. Neuron 68, 87-98 (2010)

chain by Paul Ellison at the Lawrence Berkeley National Laboratory in California and his co-workers. They made the isotopes by hitting targets of plutonium-242 with an intense beam of calcium- 48 nuclei, setting off a chain of decays from a nucleus of element 114 .

The isotopes' lifetimes ranged from eight-thousandths of a second to just over three minutes. Creating such shortlived isotopes was necessary to generate several examples of the heaviest elements before the nuclei fissioned into two similar-sized parts.

Phys. Rev. Lett. 105, 182701 (2010)

\section{EVOLUTIONARY BIOLOGY}

\section{Food thieves offer a helping hand}

An African bird that robs other species of their food seems to help as well as hinder, allowing one of its victims to catch more prey.

Pied babblers

(Turdoides

bicolor; pictured left) are often fooled by fork-tailed drongos

(Dicrurus adsimilis; pictured right), which mix fake alarm calls with genuine warnings to distract the babblers, then make off with their food. Andrew Radford at the University of Bristol, UK, and his team studied the birds in the wild, and played back drongo recordings to babblers. They found that babblers captured more prey when reassured by the regular 'twank' noises of real or recorded drongos than when there were no drongos standing guard.

This 'sentinel' calling probably arose as a means of manipulating babblers, but the benefits it brings to both species may mean that the birds' relationship is transitioning from parasitic to mutualistic, the authors suggest.

Evolution doi:10.1111/j.1558$5646.2010 .01180 . x(2010)$

\section{DNATURE.COM}

For the latest research published by Naturevisit:

www.nature.com/latestresearch 